Article

\title{
Preparation of Pd-Diimine@SBA-15 and Its Catalytic Performance for the Suzuki Coupling Reaction
}

\author{
Jiahuan Yu ${ }^{1,+}$, An Shen ${ }^{2,+}$, Yucai Cao ${ }^{2, *}$ and Guanzhong Lu ${ }^{1,3, *}$ \\ 1 Research Institute of Applied Catalysis, School of Chemical and Environmental Engineering, \\ Shanghai Institute of Technology, Shanghai 200235, China; hotta725@163.com \\ 2 State Key Laboratory of Polyolefins and Catalysis, Shanghai Key Laboratory of Catalysis Technology for \\ Polyolefins and Organic Chemistry Division, Shanghai Research Institute of Chemical Industry, \\ 345 East Yunling Road, Shanghai 200062, China; 15921959294@126.com \\ 3 Key Laboratory for Advanced Materials and Research Institute of Industrial Catalysis, \\ East China University of Science and Technology, Shanghai 200237, China \\ * Correspondence: caoyc@srici.cn (Y.C.); gzhlu@ecust.edu.cn (G.L.); \\ Tel.: +86-139-1872-5152 (Y.C.); +86-21-64252827 (G.L.) \\ $\dagger$ These authors contributed equally to this work. \\ Academic Editor: Ioannis D. Kostas \\ Received: 1 October 2016; Accepted: 17 November 2016; Published: 24 November 2016
}

\begin{abstract}
A highly efficient and stable Pd-diimine@SBA-15 catalyst was successfully prepared by immobilizing Pd onto diimine-functionalized mesoporous silica SBA-15. With the help of diimine functional groups grafted onto the SBA-15, Pd could be anchored on a support with high dispersion. Pd-diimine@SBA-15 catalyst exhibited excellent catalytic performance for the Suzuki coupling reaction of electronically diverse aryl halides and phenylboronic acid under mild conditions with an ultralow amount of Pd $(0.05 \mathrm{~mol} \% \mathrm{Pd})$. When the catalyst amount was increased, it could catalyze the coupling reaction of chlorinated aromatics with phenylboronic acid. Compared with the catalytic performances of Pd/SBA-15 and Pd-diimine@SiO ${ }_{2}$ catalysts, the Pd-diimine@SBA-15 catalyst exhibited higher hydrothermal stability and could be repeatedly used four times without a significant decrease of its catalytic activity.
\end{abstract}

Keywords: Pd-diimine@SBA-15; catalyst preparation; functionalization of SBA-15; Suzuki coupling reaction; manufacture of biphenyl compounds

\section{Introduction}

Palladium is one of the most versatile and widely applied catalysts for the construction of carbon-carbon bonds in Heck, Suzuki, Sonogashira, or Stille coupling reaction. As a homogeneous catalyst, Pd with phosphine ligands, carbene ligands, and other coordinates have often exhibited a higher turnover number (TON) and better catalytic activity for inactive chloride substances, especially in the Suzuki coupling reaction [1-7]. However, the homogeneous catalytic system may cause greater difficulties, including purification of final products and recycling of the expensive catalysts in large-scale applications. Fortunately, the heterogeneous catalytic system could be an alternative strategy to overcome the above difficulties [8].

The palladium nanoparticle supported on polymeric organic [9-13] or inorganic [14-18] supports is a high-efficient heterogeneous catalyst, and its catalytic activity strongly depends on the size of $\mathrm{Pd}$ particles. Some heterogeneous Pd catalysts showed lower catalytic activity due to leaching of Pd species or aggregation of nanoparticles. To disperse and stabilize the supported palladium nanoparticles, the nature of supports, advanced preparation methods, and essential functionalization should be taken into proper consideration $[19,20]$. 
Palladium nanoparticles immobilized on inorganic materials such as silica [21-23], carbon [24], and metal oxides [25] could be one promising solution. Owing to highly ordered mesoporous structures with regular channels, larger surface areas and pore size, thicker walls, and higher hydrothermal stability, mesoporous silica SBA-15 is a desirable solid support for Pd nanoparticles [26]. In addition, palladium nanoparticles supported on the channels of SBA-15 with two-dimensional (2D) hexagonal structures can be ideally dispersed, to effectively prevent the aggregation of palladium nanoparticles $[27,28]$.

Moreover, the functional groups (such as amino, thiol, and vinyl groups) can usually be incorporated on the mesoporous walls [29]. Some of functional groups have been shown to act as anchoring sites for palladium species, thus providing additional stabilization. For example, Crudden et al. [30,31] anchored Pd on mercaptopropyl-modified mesoporous SBA-15. Their leaching study illustrated the importance of the thiol ligand to retain $\mathrm{Pd}$ on the support surface. An efficient and reusable catalyst SBA-15/CCPy/Pd(II) could also be synthesized by grafting melamine-bearing pyridine groups onto SBA-15 [32]. Undoubtedly, the imine groups possess good coordinating ability in a catalytic reaction, and the diimine groups might intensify its coordinating ability.

The Suzuki coupling reaction is a typical carbon-carbon bond-forming process, and has become one of the most powerful and convenient means in the fields of agrochemistry, pharmaceutical chemistry, materials, and synthetic chemistry [33]. Despite the successful application of the Suzuki coupling reaction in homogeneous catalytic systems, the highly efficient and stable heterogeneous catalysts are still in great demand, and the activities and stabilities of heterogeneous catalysts for the Suzuki coupling reaction require be improvement.

Herein, we describe our design and preparation of the Pd-diimine@SBA-15 catalyst for the Suzuki coupling reaction by immobilizing Pd species onto diimine-functionalized mesoporous SBA-15 silica (Scheme 1), in which Pd ions were dispersed atomically onto the functionalized mesoporous SBA-15. The scope and limitations of Pd-diimine@SBA-15 for Suzuki coupling reactions of electronically diverse aryl halides and phenylboronic acid were also evaluated.
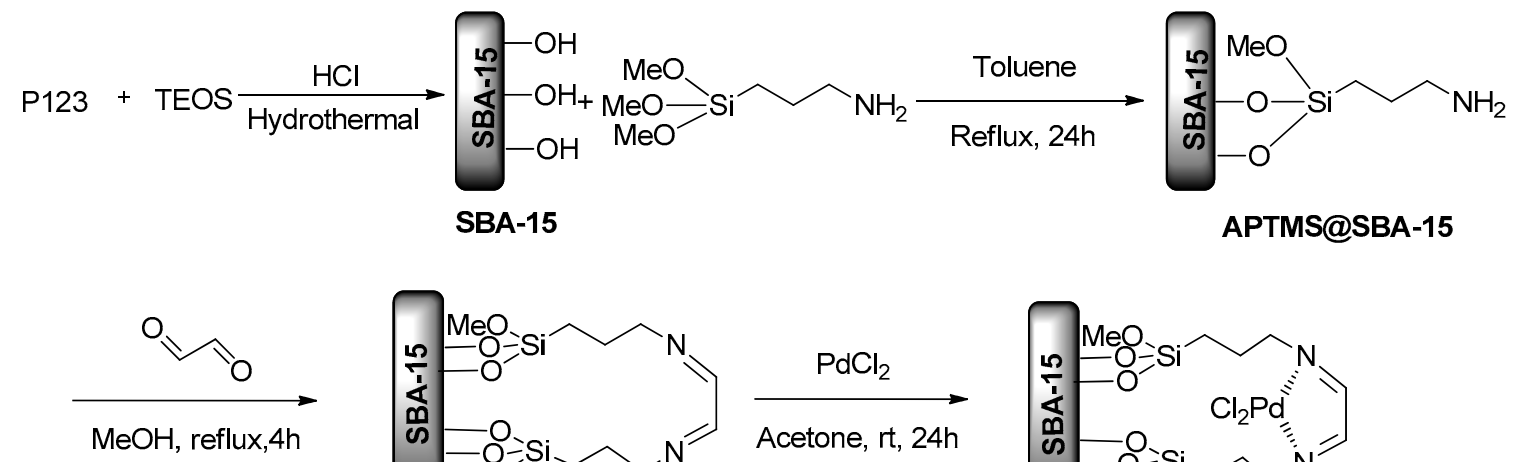

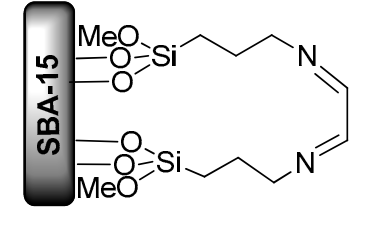

diimine@SBA-15
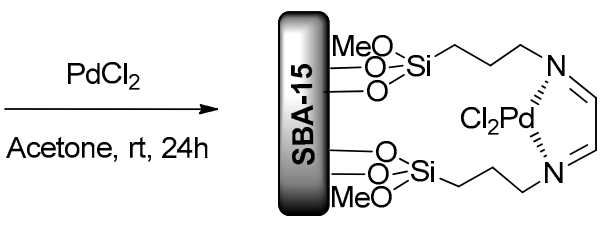

Pd-diimine@SBA-15

Scheme 1. Schematic diagram of Pd-diimine@SBA-15 fabrication.

\section{Results and Discussions}

\subsection{Structure and Textural Properties of Samples}

The Fourier-transform infrared (FT-IR) spectra of SBA-15, 3-aminopropyl trimethoxysilane (APTMS)@SBA-15, diimine@SBA-15, and Pd-diimine@SBA-15 are shown in Figure 1. The peaks at $600-1200 \mathrm{~cm}^{-1}$ can be attributed to the vibration of Si-O groups in the mesoporous silica framework. The absorption bands of SBA-15-based materials at 1083, 801, and $466 \mathrm{~cm}^{-1}$ are attributed to the $\mathrm{Si}-\mathrm{O}-\mathrm{Si}$ anti-stretching vibration, the $\mathrm{Si}-\mathrm{O}-\mathrm{Si}$ stretching vibration, and the bending vibration of $\mathrm{Si}-\mathrm{O}$, respectively [34]. Meanwhile, the band around $956 \mathrm{~cm}^{-1}$ should be attributed to the bending vibration 
of Si-O-H in SBA-15 [35]. In the FT-IR spectrum of APTMS@SBA-15, there are the characteristic bands of $-\mathrm{NH}_{2}$ at 1645 and $1538 \mathrm{~cm}^{-1}$. For the diimine@SBA-15 sample, the absorption peak at $1656 \mathrm{~cm}^{-1}$ is observed and attributed to the characteristic peaks of diimine, due to the presence of the $\mathrm{C}=\mathrm{N}$ bond. After diimine@SBA-15 coordinated with Pd, this IR absorption peak shifted from 1656 to $1622 \mathrm{~cm}^{-1}$, which is indicative for the formation of a Pd-ligand bond [22,36]. The results above imply the presence of diimine bonded on the surface of SBA-15, and that the molecular structure of these functional moieties can be perfectly retained in the complex of Pd-diimine@SBA-15.

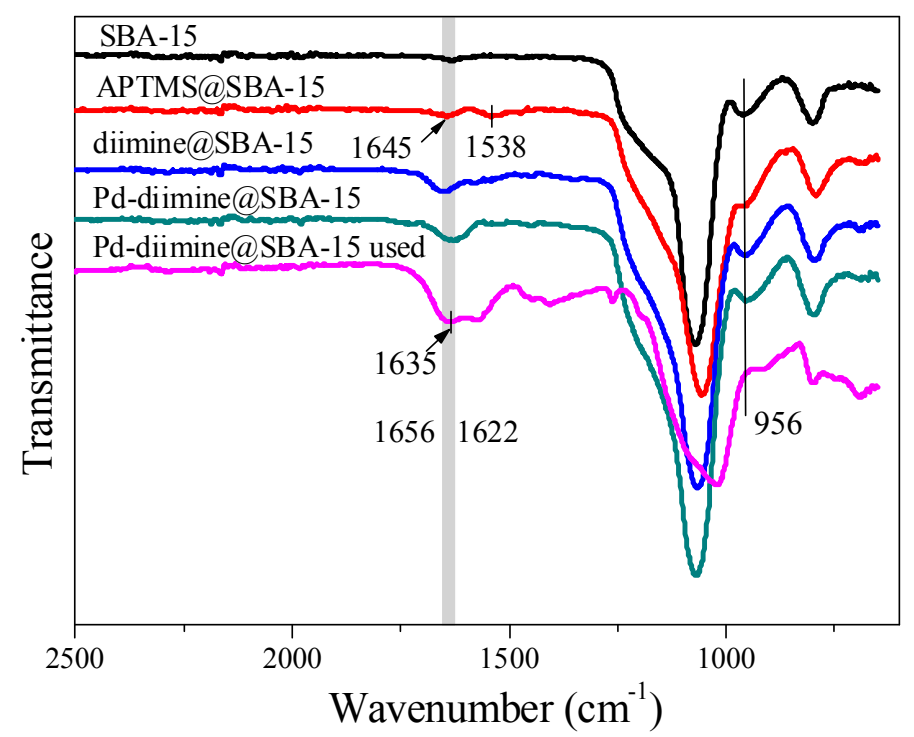

Figure 1. Fourier-transform infrared (FT-IR) spectra of SBA-15, 3-aminopropyl trimethoxysilane (APTMS)@SBA-15, diimine@SBA-15, and Pd-diimine@SBA-15 (fresh and used repeatedly four times).

The Pd-diimine@SBA-15 catalyst before and after reactions were tested by ${ }^{13} \mathrm{C}$ cross-polarization magic-angle spinning (CPMAS) solid-state NMR, and the results are shown in Figure 2. ${ }^{13} \mathrm{C}\left\{{ }^{1} \mathrm{H}\right\}$ CPMAS NMR spectrum of fresh Pd-diimine@SBA-15 catalyst exhibits peaks at 10.1 ( $\mathrm{CH}_{2} \mathrm{Si}$ groups), $22.4\left(\mathrm{CH}_{2}\right.$ groups), and $50.6 \mathrm{ppm}\left(\mathrm{CH}_{2}\right.$ groups in $\alpha$-position of $\mathrm{C}=\mathrm{N}$ bond). The other broad peak at $169.8 \mathrm{ppm}$ could be attributed to $\mathrm{C}=\mathrm{N}$ function groups. After this catalyst was repeatedly used four times, the ${ }^{13} \mathrm{C}\left\{{ }^{1} \mathrm{H}\right\}$ CPAMS NMR spectrum of Pd-diimine@SBA- 15 catalyst is hardly changed. The additional singlet at $128.5 \mathrm{ppm}$ might correspond to the presence of a biphenyl product. This shows that the diimine ligands remain on the catalyst and were not hydrolyzed after the catalytic reactions.

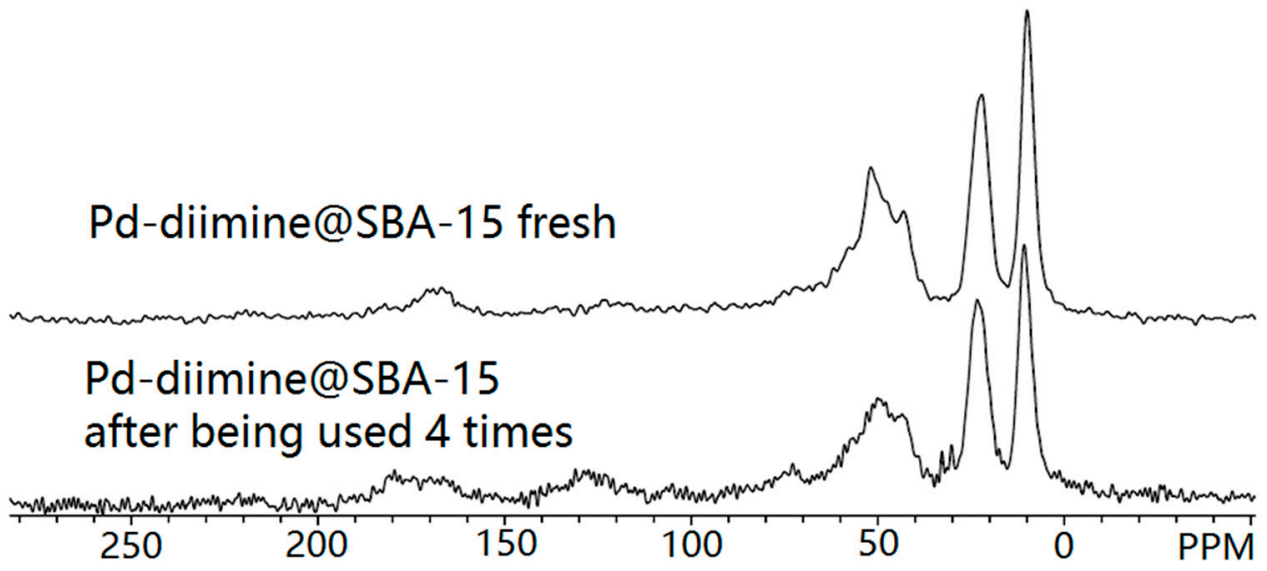

Figure 2. ${ }^{13} \mathrm{C}$ cross-polarization magic-angle spinning (CPMAS) NMR spectra of Pd-diimine@SBA-15 before and after being repeatedly used four times. 
The N contents in APTMS@SBA-15 and diimine@SBA-15 were tested by element analysis; the former was $2.05 \mathrm{mmol} / \mathrm{g}$ and the latter was $1.92 \mathrm{mmol} / \mathrm{g}$. Thus, the loadings of APTMS and diimine were 2.05 and $0.96 \mathrm{mmol} / \mathrm{g}$, respectively. The Pd content in the Pd-diimine@SBA-15 sample was $5.8 \mathrm{wt} \%$, determined by inductively coupled plasma optical emission spectrometry (ICP-OES). The oxidation state of Pd in the Pd-diimine@SBA-15 catalyst was investigated by the $\mathrm{X}$-ray photoelectron spectroscopy (XPS) technique, and the results are shown in Figure 3. In the fresh Pd-diimine@SBA-15 sample, the peak at $3 \mathrm{~d}_{3 / 2} \mathrm{BE}=337.8 \mathrm{eV}\left(\right.$ or $\left.3 \mathrm{~d}_{5 / 2} \mathrm{BE}=343.0 \mathrm{eV}\right)$ corresponds to the $\mathrm{Pd}(\mathrm{II})$ ions [18], and the peak at $336.5 \mathrm{eV}$ (or $3 \mathrm{~d}_{5 / 2} \mathrm{BE}=341.7 \mathrm{eV}$ ) corresponds to the $\mathrm{Pd}(\mathrm{II})$ ions in the diimine-Pd(II) complex [27]. This shows that the Pd(II) ions existed in two kinds of chemical environments, and $\mathrm{Pd}(\mathrm{II})$ was not reduced to $\mathrm{Pd}(0)$ during the synthesis.

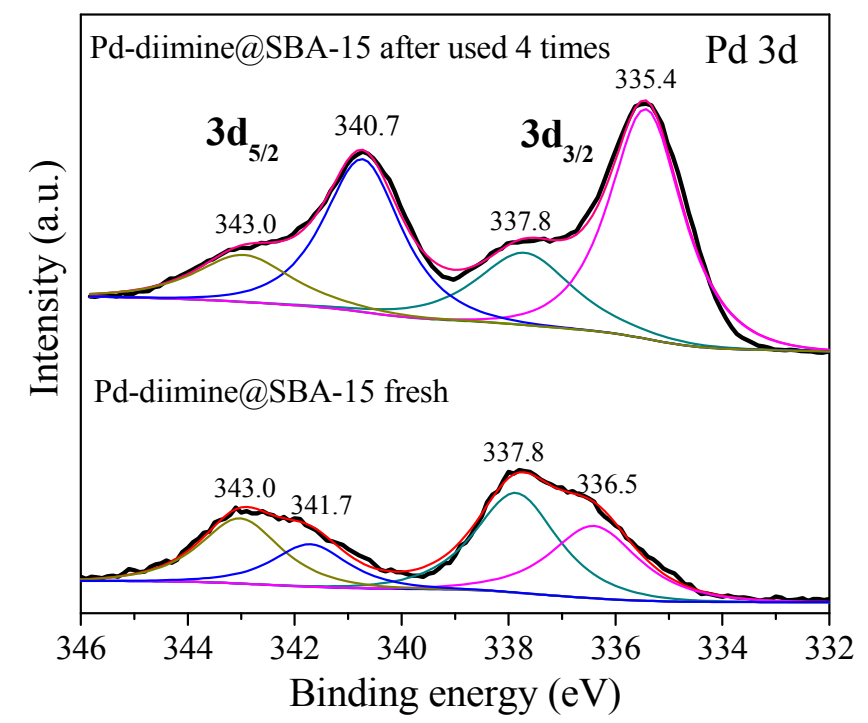

Figure 3. X-ray photoelectron spectroscopy (XPS) spectra of Pd-diimine@SBA-15 (fresh and after being used four times).

The $\mathrm{N}_{2}$ sorption isotherms and pore-size distribution curves of the samples are displayed in Figure 4, and their textural parameters (Brunauer-Emmett-Teller (BET) surface areas, pore volumes, and pore diameters) are listed in Table 1. As shown in Figure 4, all the isotherms exhibited a typical type IV isotherm with an $\mathrm{H}_{1}$ hysteresis loop starting from $P / P_{0}=0.6$. This is the characteristic of mesoporous SBA-15 with ordered pore structures [37], which is quite important to disperse and stabilize the supported palladium species. Compared with the BET surface area $\left(641 \mathrm{~m}^{2} / \mathrm{g}\right)$ of SBA-15, the surface area of Pd-diimine@SBA-15 was decreased to $351 \mathrm{~m}^{2} / \mathrm{g}$ after SBA-15 was functionalized. Meanwhile, its pore volume was decreased from 0.96 to $0.48 \mathrm{~cm}^{3} / \mathrm{g}$, average pore diameter was decreased from 6.35 to $5.50 \mathrm{~nm}$, and most probable pore diameter was decreased from 10.5 to $6.90 \mathrm{~nm}$. These results are in good agreement with the fact that the surface of mesoporous SBA-15 has been modified successfully by diimine groups. Pd species have entered into the channels of the SBA-15 materials, resulting in the decrease in its pore size. 


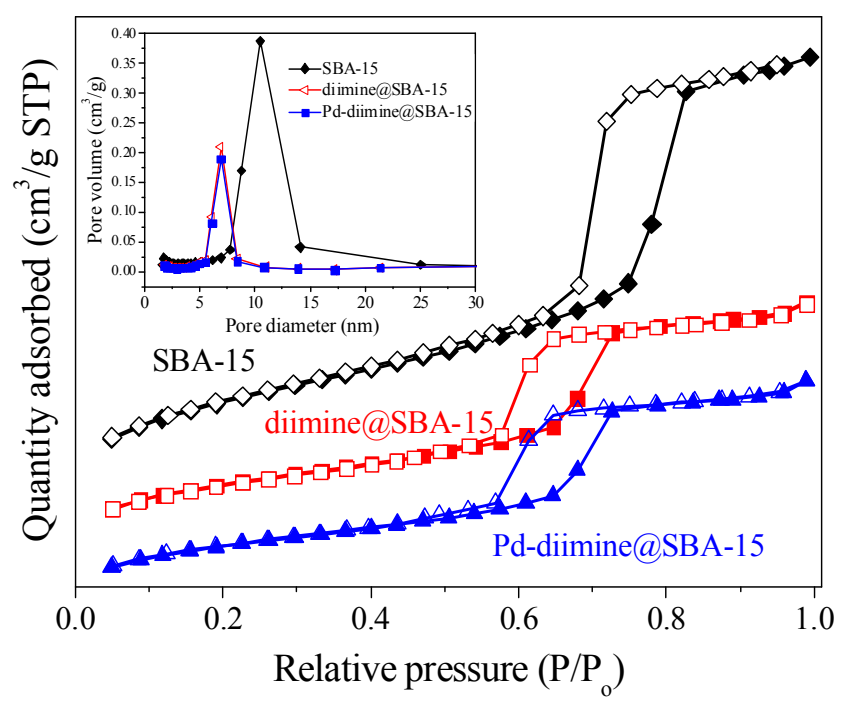

Figure 4. $\mathrm{N}_{2}$ sorption isotherms and pore-size distribution curves of SBA-15, diimine@SBA-15, and Pd-diimine@SBA-15.

Table 1. Textural parameters of SBA-15, diimine@SBA-15, and Pd-diimine@SBA-15.

\begin{tabular}{ccccc}
\hline \multirow{2}{*}{ Sample } & BET Surface Area $\left(\mathbf{m}^{2} / \mathbf{g}\right)$ & Pore Volume $\left(\mathbf{c m}^{\mathbf{3}} / \mathbf{g}\right)$ & \multicolumn{2}{c}{ Pore Diameter $(\mathbf{n m})$} \\
\cline { 4 - 5 } & & & Average & Most Probable \\
\hline SBA-15 & 641 & 0.96 & 6.35 & 10.5 \\
diimine@SBA-15 & 398 & 0.53 & 5.58 & 6.90 \\
Pd-diimine@SBA-15 & 351 & 0.48 & 5.50 & 6.90 \\
\hline
\end{tabular}

The X-ray diffraction (XRD) patterns of SBA-15 and Pd-diimine@SBA-15 are shown in Figure 5. The SBA-15 sample exhibits three peaks at $2 \theta=0.9^{\circ}, 1.6^{\circ}$, and $1.9^{\circ}$, which correspond to (100), (110), and (200) facets, the characteristic diffraction peaks of mesoporous SBA-15 with a hexagonal geometry [38]. After SBA-15 was modified with diimine, its peak of (110) facet shifted to a lower angle and its intensity was obviously weakened. Compared with SBA-15, the diffraction peak intensities of (110) and (200) facets for Pd-diimine@SBA-15 were greatly decreased. These results are consistent with the fact that Pd-diimine@SBA-15 has smaller surface area, pore volume, and pore size than the SBA-15 sample. The reduced ordering degree of the mesoporous structure is mainly attributed to the occupation of Pd species in the pore channels [39]. Thus, it is reasonable to conclude that Pd species have been dispersed well in the pore channels of SBA- 15.

In the XRD patterns of SBA-15, Pd/SBA-15, and Pd-diimine@SBA-15 (Figure 5 inset), a very broad and typical diffraction peak of silica is slightly visible around $2 \theta=25^{\circ}$. That is, there is no major change in the crystallinity of SBA-15 after diimine-functionalization and Pd immobilization. Furthermore, the diffraction peaks of Pd species cannot be detected, which also shows that the Pd species were immobilized into the pore channels of SBA-15 in the atom dispersion [9], and no crystal Pd species existed in the sample. 


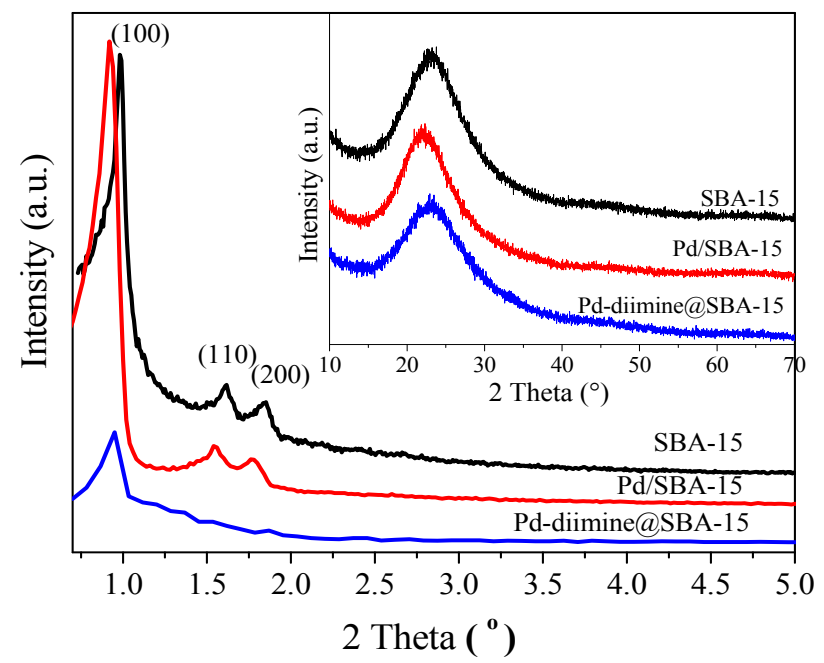

Figure 5. Small-angle X-ray diffraction (SA-XRD) and XRD patterns of SBA-15, Pd/SBA-15, and Pd-diimine@SBA-15.

As shown in the SEM images of Figure 6A, the SBA-15 sample is that with the bagel-shaped particles with relatively uniform sizes. After being functionalized with diimine and $\mathrm{Pd}$, the shape of SBA-15 is unchanged (Figure 6B). To investigate the role of diimine groups in the catalyst, we prepared the Pd/SBA-15 sample as a comparison. The Pd/SBA-15 sample was synthesized by a method similar to Pd-dimine@SBA-15, but without using 3-aminopropyl trimethoxysilane and glyoxal. The TEM image of the Pd-diimine@SBA-15 sample (Figure 6C) reveals that no palladium nanoparticles can be observed in the pores, which shows the $\mathrm{Pd}^{2+}$ ions have coordinated with two $\mathrm{N}$ atoms in diimine@SBA-15. Unlike the Pd-diimine@SBA-15 sample, more Pd nanoparticles in the pores of SBA-15 can be observed in the TEM image of Pd/SBA-15 (Figure 6D), which shows that the growth of Pd nanoparticles can be inhibited by Pd ions coordinating with diimine anchored on SBA-15.

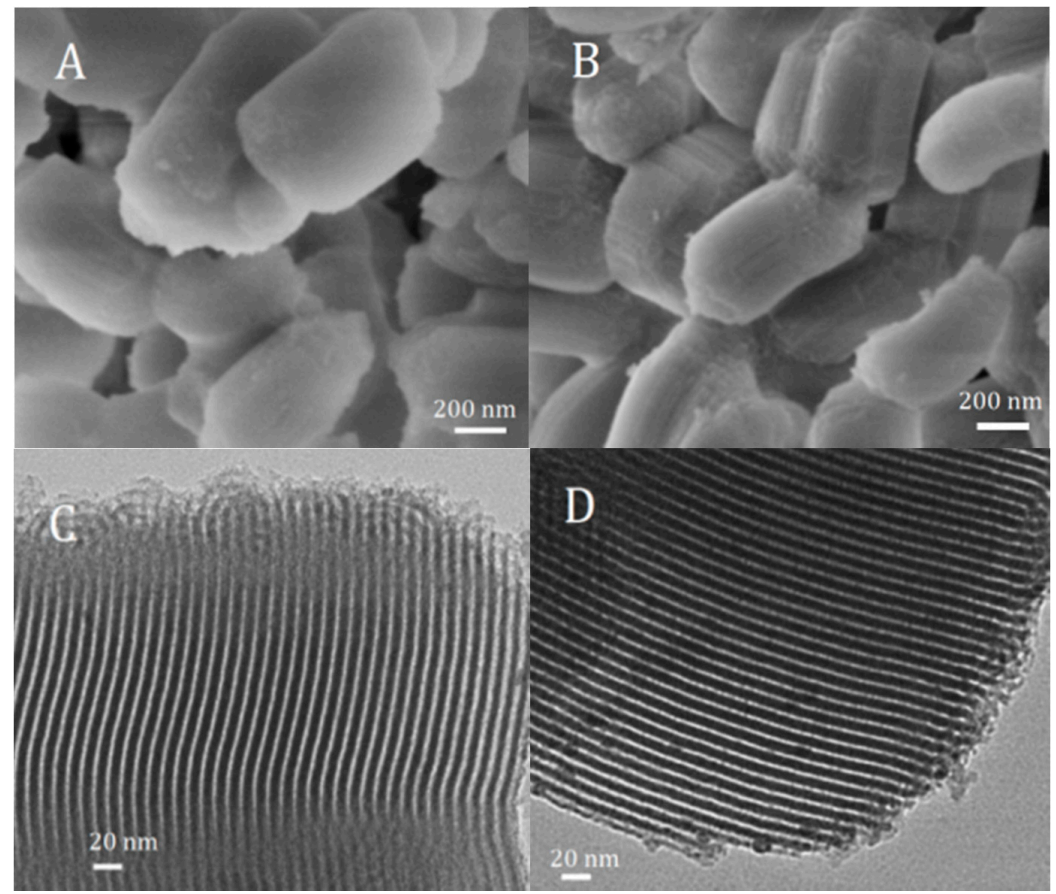

Figure 6. SEM images of (A) SBA-15 and (B) Pd-diimine@SBA-15, and TEM images of (C) Pd-diimine@SBA-15 and (D) Pd/SBA-15. 


\subsection{Catalytic Activities of Pd-Diimine@SBA-15 for Suzuki Coupling Reactions}

The catalytic activity of Pd-diimine@SBA-15, SBA-15, and $\mathrm{PdCl}_{2}$ were tested for the Suzuki coupling reaction of para-bromotoluene with phenylboronic acid at $80{ }^{\circ} \mathrm{C}$, and the results are listed in Table 2. The reaction could not occur over SBA-15 (Table 2, entry 1), and 85\% yield could be obtained on the $\mathrm{PdCl}_{2}$ homogenous catalyst (Table 2, entry 2). Using the Pd-diimine@SBA-15 catalyst, almost the same yield as that on the $\mathrm{PdCl}_{2}$ catalyst was achieved. The effect of alkalinity in the reaction system on the stability of mesoporous silica SBA-15 and the catalytic activity of the Pd-diimine@SBA-15 catalyst was tested. The results show that stronger alkalinity could increase the product yield. For instance, $91 \%$ yield was obtained by adding $\mathrm{KOH}$ after $4 \mathrm{~h}$, while only $84 \%$ yield could be reached by adding $\mathrm{K}_{2} \mathrm{CO}_{3}$ after $24 \mathrm{~h}$ (Table 2, entries 3-5).

Table 2. Effect of base on the Suzuki coupling reaction of para-bromotoluene with phenylboronic acid over the Pd-diimine@SBA-15 catalyst at $80{ }^{\circ} \mathrm{C}$ (a).

\begin{tabular}{|c|c|c|c|c|c|c|}
\hline Entry & Catalyst & Base & Time (h) & Conversion $(\%)$ & Selectivity (\%) & Yield (\%) (b) \\
\hline 1 & SBA-15 & $\mathrm{K}_{2} \mathrm{CO}_{3}$ & 12 & 0 & 0 & 0 \\
\hline 2 & $\mathrm{PdCl}_{2}(0.05 \mathrm{~mol} \% \mathrm{Pd})$ & $\mathrm{K}_{2} \mathrm{CO}_{3}$ & 12 & 85 & 100 & 85 \\
\hline 3 & Pd-diimine@SBA-15 & $\mathrm{K}_{2} \mathrm{CO}_{3}$ & 24 & 84 & 100 & 84 \\
\hline 4 & Pd-diimine@SBA-15 & $\mathrm{K}_{3} \mathrm{PO}_{4}$ & 12 & 88 & 100 & 88 \\
\hline 5 & Pd-diimine@SBA-15 & $\mathrm{KOH}$ & 4 & 91 & 100 & 91 \\
\hline
\end{tabular}

(a) Reaction condition: $3 \mathrm{mmol}$ 4-bromotoluene, $3.3 \mathrm{mmol}$ phenylboronic acid, $4.5 \mathrm{mmol}$ base, solvent (i-PrOH $\left./ \mathrm{H}_{2} \mathrm{O}=3 \mathrm{~mL} / 3 \mathrm{~mL}\right), 3 \mathrm{mg}$ catalyst $(0.05 \mathrm{~mol} \% \mathrm{Pd}$ ); (b) gas chromatography (GC) yield based on 4-bromotoluene.

However, the alkali solution might damage the structure of mesoporous SBA-15 during the Suzuki coupling reaction. The TEM, SEM, and XRD analyses for Pd-diimine@SBA-15 treated with $\mathrm{KOH}$ and $\mathrm{K}_{3} \mathrm{PO}_{4}$ during the Suzuki coupling reaction were carried out, and their results are shown in Figure 7. The TEM and SEM pictures of Pd-diimine@SBA-15 used in the KOH solution display irregular structures and Pd crystallites (Figure 7A,C). However, Pd-diimine@SBA-15 used in the $\mathrm{K}_{3} \mathrm{PO}_{4}$ solution still retained the basic shape of mesoporous SBA-15 (Figure 7D) and abundant wormlike mesoporous structures can be clearly observed (Figure 7B inset). The Pd nanoparticles can be observed in Figure 7A (inset) but not in Figure 7B (inset). As shown in Figure 7, after the Pd-diimine@SBA-15 catalyst was treated in the alkali $\left(\mathrm{KOH}\right.$ or $\left.\mathrm{K}_{3} \mathrm{PO}_{4}\right)$ solution, the dispersing diffraction peaks of $\mathrm{Pd}^{\circ}$ at $2 \theta=\sim 40^{\circ}$ can be observed. Unlike the XRD pattern of the sample treated in the $\mathrm{K}_{3} \mathrm{PO}_{4}$ solution, the sample treated in the $\mathrm{KOH}$ solution has three weak diffraction peaks at $2 \theta=\sim 40^{\circ}, \sim 46^{\circ}$, and $\sim 68^{\circ}$, which shows that the sample treated with the $\mathrm{KOH}$ solution has the larger size $(2.6 \mathrm{~nm}$, estimated by Scherrer equation) of $\mathrm{Pd}^{0}$ crystallites than that $(2.1 \mathrm{~nm})$ of the sample treated with the $\mathrm{K}_{3} \mathrm{PO}_{4}$ solution. These results show that that active $\mathrm{Pd}$ species were dispersed quite well on the support, though the mesoporous structure of SBA-15 had been damaged after being treated in the $\mathrm{KOH}$ solution. Thus, it is reasonable that the Pd-diimine@SBA-15 catalyst could maintain its catalytic activity due to the high dispersion of $\mathrm{Pd}$. 

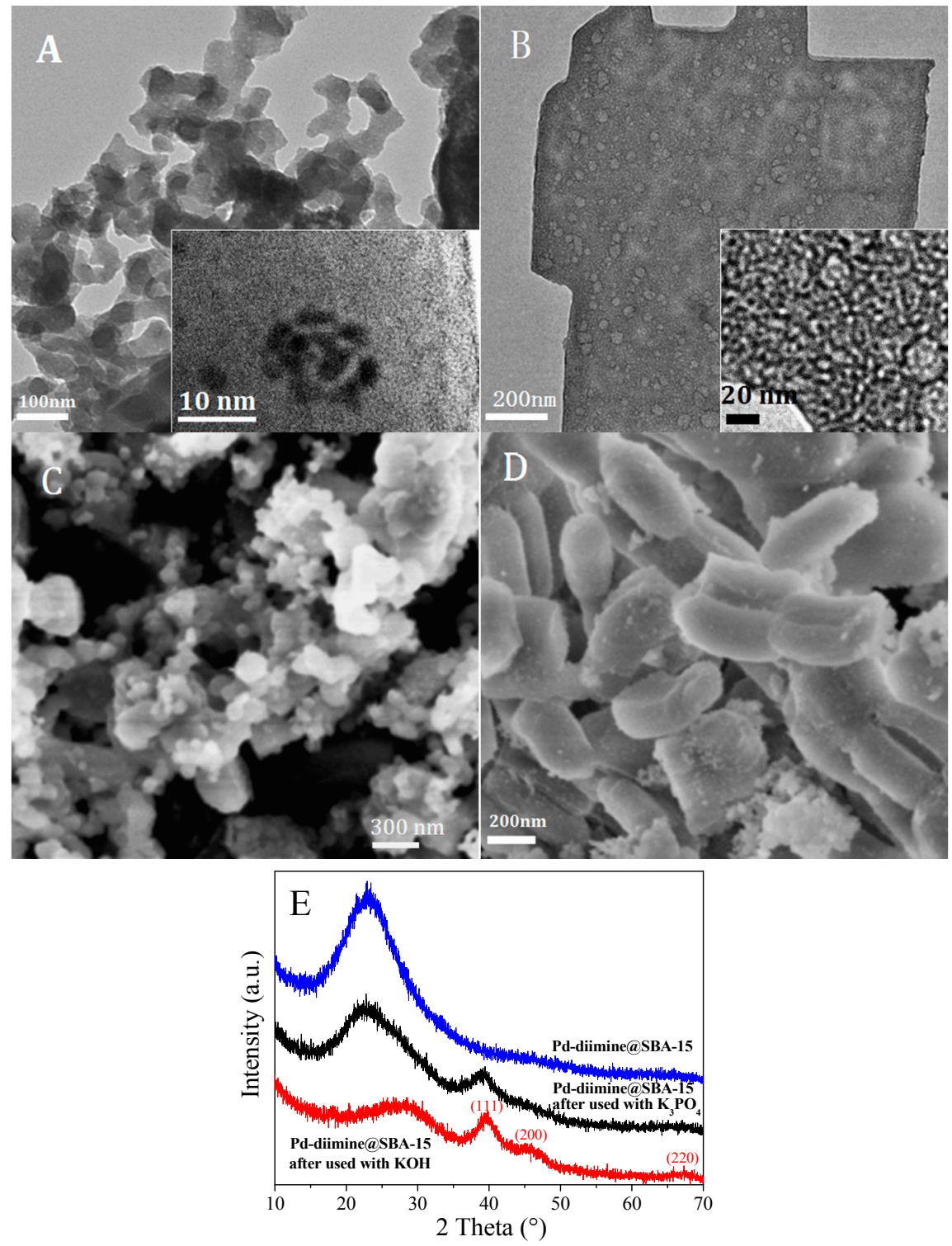

Figure 7. TEM images of Pd-diimine@SBA-15 after use with (A) $\mathrm{KOH}$ and (B) $\mathrm{K}_{3} \mathrm{PO}_{4}$; SEM image of Pd-diimine@SBA-15 after use with (C) KOH and (D) $\mathrm{K}_{3} \mathrm{PO}_{4}$, and (E) their XRD patterns.

To evaluate the scope and limitation of the Pd-diimine@SBA-15 catalyst for Suzuki coupling reactions, the reactions of electronically diverse aryl halides and phenylboronic acid were further examined under optimized condition (Table 3). High yields can be obtained for the coupling reactions of bromobenzene with electron-withdrawing and -donating substituents and phenylboronic acid (Table 3, entries 1-8). The better catalytic activity of Pd-diimine@SBA-15 might be contributed to the good dispersion of Pd in the pore channels and high surface area of the SBA-15 support. For instance, the biphenyl yield reached $87 \%$ for the reaction of bromobenzene and phenylboronic acid at $80{ }^{\circ} \mathrm{C}$ for $12 \mathrm{~h}$ (Table 3, entry 1). When an aryl bromide including an electron-withdrawing groups (as bromopentafluorobenzene) was used as a reactant, only $27 \%$ yield was obtained at $80^{\circ} \mathrm{C}$ for $12 \mathrm{~h}$ (Table 3, entry 9) due to the homocoupling of bromopentafluorobenzene, and only $33 \%$ selectivity for product. When 2-bromopyridine was used as a reactant, only $13 \%$ yield was achieved (Table 3, entry 10). These results indicate that the Pd-diimine@SBA-15 catalyst can easily catalyze the Suzuki coupling reaction of the electron-rich Br-including aromatic compounds with phenylboronic acid. When the amount of catalyst was increased to $60 \mathrm{mg}$ ( $1 \mathrm{~mol} \% \mathrm{Pd})$, aryl chlorides became 
applicable substrates (Table 3, entries 11 and 12); for instance, 20\% yield was obtained for the coupling of activated (electron-deficient) 4-nitrochlorobenzene and phenylboronic acid (Table 3, entry 12).

Table 3. Suzuki coupling reactions of various aryl halides $(X)$ and phenylboronic acid over Pd-diimine@SBA-15catalyst (a).

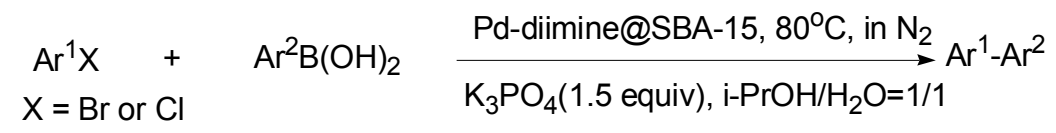

\begin{tabular}{|c|c|c|c|c|c|c|}
\hline Entry & Aryl X & Boronic acid & Time (h) & Conversion $(\%)$ & Selectivity (\%) & Yield (\%) (b) \\
\hline 1 & & & 12 & 87 & 100 & $87(87)$ \\
\hline 2 & & & 12 & 88 & 100 & $88(84)$ \\
\hline 3 & & $-\mathrm{B}(\mathrm{OH})_{2}$ & 8 & 91 & 100 & $91(87)$ \\
\hline 4 & & $\mathrm{~B}(\mathrm{OH})_{2}$ & 8 & 91 & 100 & $91(88)$ \\
\hline 5 & & $-\mathrm{B}(\mathrm{OH})_{2}$ & 6 & 87 & 100 & $87(79)$ \\
\hline 6 & & $-\mathrm{B}(\mathrm{OH})_{2}$ & 10 & 84 & 100 & $84(77)$ \\
\hline 7 & & $-\mathrm{B}(\mathrm{OH})_{2}$ & 3 & 88 & 100 & $88(81)$ \\
\hline 8 & & $-\mathrm{B}(\mathrm{OH})_{2}$ & 4 & 99 & 100 & $99(96)$ \\
\hline 9 & & $-\mathrm{B}(\mathrm{OH})_{2}$ & 12 & 83 & 33 & 27 \\
\hline 10 & & $\mathrm{~B}(\mathrm{OH})_{2}$ & 4 & 13 & 100 & 13 \\
\hline 11 & & & 4 & 2 & 100 & 2 (c) \\
\hline 12 & & $-\mathrm{B}(\mathrm{OH})_{2}$ & 4 & 20 & 100 & $20(c)$ \\
\hline
\end{tabular}

(a) Reaction condition: $3 \mathrm{mg}$ catalyst $(0.05 \mathrm{~mol} \% \mathrm{Pd}), \mathrm{ArX}(3.0 \mathrm{mmol}), \mathrm{ArB}(\mathrm{OH})_{2}\left(3.3 \mathrm{mmol}, 1.1\right.$ equiv), $\mathrm{K}_{3} \mathrm{PO}_{4}$ (4.5 mmol, 1.5 equiv), i-PrOH/ $\mathrm{H}_{2} \mathrm{O}(3 \mathrm{~mL} / 3 \mathrm{~mL})$; (b) GC yield based on $\mathrm{ArX}$ and isolated yield shown in brackets; (c) $60 \mathrm{mg}$ catalyst ( $1 \mathrm{~mol} \%$ Pd).

Based on the research results above, the possible mechanism of the Suzuki coupling reaction of aryl halide and phenylboronic acid over Pd-diimine@SBA-15 can be described as Scheme 2 [32,40]. In Scheme 2, there are three main stages in the mechanism of the Suzuki cross-coupling reaction over Pd-diimine@SBA-15: the oxidative addition of substrate, transmetalation, and reductive elimination to produce the final product, in which the catalytic cycle of $\mathrm{Pd}(0) / \mathrm{Pd}(\mathrm{II})$ occurred. 


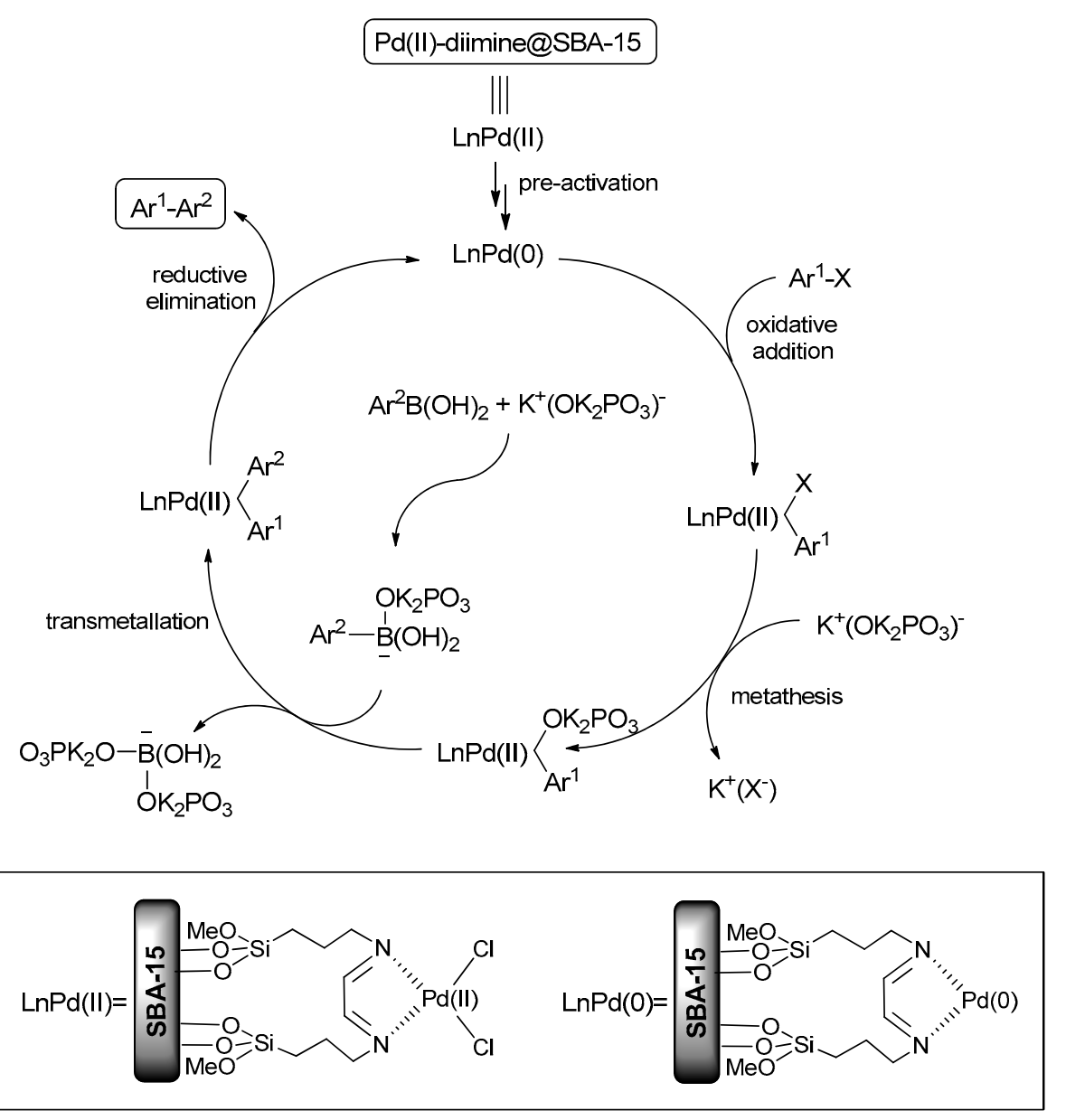

Scheme 2. Possible mechanism of the Suzuki coupling reaction over Pd-diimine@SBA-15.

\subsection{Repeated Use of the Pd-Diimine@SBA-15 Catalyst}

The catalyst was separated immediately by filtration after the reaction was finished, and was washed by deionized water, ethanol, and diethyl ether successively. After drying in air, the recovered catalyst could be used repeatedly in the Suzuki coupling reaction. To facilitate the recycling of the catalyst, the reaction scale was magnified to $50 \mathrm{mg}$ catalyst. As shown in Table 4 and Figure 8, after the Pd-diimine@SBA-15 catalyst was repeatedly reused four times, its catalytic performance had not decreased based on the yield obtained (first $87 \%$, second $87 \%$, third $86 \%$, and fourth $85 \%$ ), in which the slight reduction of yield should be ascribed to the loss of the catalyst in the process of recovery and washing. As a comparison, the performances of Pd/SBA- 15 and Pd-diimine@SiO catalysts after repeated use were also measured. With an increase in recycle times, the catalytic activities of Pd/SBA-15 and Pd-diimine@SiO ${ }_{2}$ catalysts were reduced gradually, in which the stability of Pd-diimine@SiO 2 was higher than that of Pd/SBA-15. For the Pd/SBA-15 catalyst, the yield of first run was $84 \%$, and after the fourth run its yield fell to $19 \%$. 
Table 4. Recyclability test of the Pd catalyst for the coupling reaction of bromobenzene and phenylboronic acid at $80^{\circ} \mathrm{C}$ for $12 \mathrm{~h}$ (a).

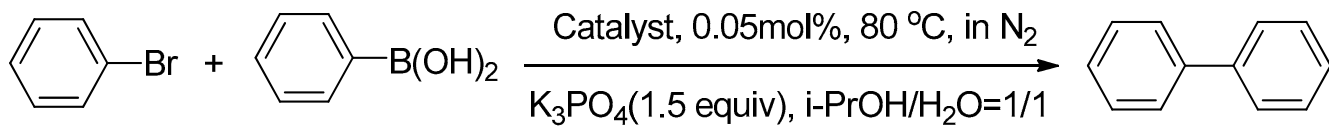

\begin{tabular}{ccccc}
\hline Catalyst & Cycle Times & Yield (b) (\%) & Pd Leaching (ppm) & Pd leaching/Pd Loading (\%) \\
\hline & 1 & 87 & 3.7 & 1.6 \\
Pd-diimine@SBA-15 & 2 & 87 & 3.0 & 1.3 \\
(5.8wt \% Pd) & 3 & 86 & 2.2 & 0.9 \\
& 4 & 85 & 1.9 & 0.8 \\
Pd/SBA-15 & 1 & 84 & 23 & 12.2 \\
$(4.7 \mathrm{wt} \%$ Pd) & 2 & 73 & 13 & 6.9 \\
& 4 & 56 & 23 & 4.8 \\
Pd-diimine@SiO 2 & 1 & 19 & 9.1 & - \\
$(5.2 \mathrm{wt} \% \mathrm{Pd})$ & 2 & 88 & - & - \\
& 3 & 87 & - & - \\
\hline
\end{tabular}

(a) Reaction condition: $50 \mathrm{mg}$ catalyst $(0.05 \mathrm{~mol} \% \mathrm{Pd}), \mathrm{ArX}(50 \mathrm{mmol}), \mathrm{ArB}(\mathrm{OH})_{2}\left(55 \mathrm{mmol}, 1.1\right.$ equiv), $\mathrm{K}_{3} \mathrm{PO}_{4}$ (75 mmol, 1.5 equiv), i-PrOH/ $\mathrm{H}_{2} \mathrm{O}(50 \mathrm{~mL} / 50 \mathrm{~mL})$; (b) GC yield based on 4-bromotoluene.

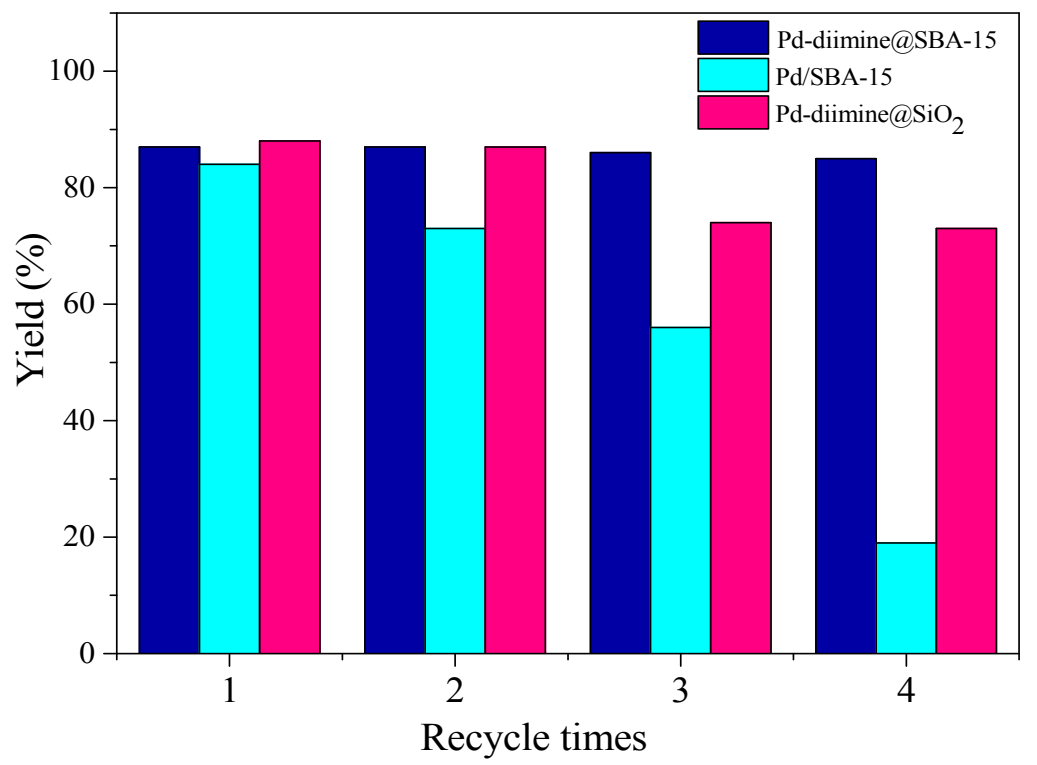

Figure 8. Repeated-use testing of the Pd catalysts for the coupling reaction of bromobenzene and phenylboronic acid at $80^{\circ} \mathrm{C}$ for $12 \mathrm{~h}$. (Reaction condition: $50 \mathrm{mg}$ catalyst $(0.05 \mathrm{~mol} \% \mathrm{Pd}), \operatorname{ArX}(50 \mathrm{mmol})$, $\mathrm{ArB}(\mathrm{OH})_{2}$ (55 mmol, 1.1 equiv), $\mathrm{K}_{3} \mathrm{PO}_{4}$ (75 mmol, 1.5 equiv), i- $\mathrm{PrOH} / \mathrm{H}_{2} \mathrm{O}(50 \mathrm{~mL} / 50 \mathrm{~mL})$ ).

The TEM image, $\mathrm{N}_{2}$ sorption isotherm curve, and the small-angle (SA)-XRD pattern were employed to evaluate the reused catalyst (Figure 9). After Pd-diimine@SBA-15 was repeatedly used four times, the TEM image (Figure 9A) still showed basic shape of SBA-15, which meant that the Pd species were still highly dispersed with some nanoparticles of $2 \sim 3 \mathrm{~nm}$. The $\mathrm{N}_{2}$ sorption isotherm and the SA-XRD pattern suggested that the 1D mesoporous structure of Pd-diimine@SBA-15 cannot be observed, but abundant wormlike mesoporous structures still exists obviously (Figure 9C). However, the TEM image of reused Pd/SBA-15 catalyst after four runs (Figure 9B) showed that $\mathrm{Pd}$ nanoparticles were aggregated on the surface of the support, and their size was $5 \sim 7 \mathrm{~nm}$. In the XPS Pd 3d spectrum of Pd-diimine@SBA-15 after being used four times (Figure 3), the small peak at $337.8 \mathrm{eV}\left(\right.$ or $3 \mathrm{~d}_{5 / 2} \mathrm{BE}=343.0 \mathrm{eV}$ ) corresponds to the $\mathrm{Pd}(\mathrm{II})$ ions, and the larger peak at $335.4 \mathrm{eV}$ 
(or $3 \mathrm{~d}_{5 / 2} \mathrm{BE}=340.7 \mathrm{eV}$ ) corresponds to $\mathrm{Pd}(0)$, which shows that a majority of $\mathrm{Pd}(\mathrm{II})$ ions were reduced to $\operatorname{Pd}(0)$ after the reaction. The FT-IR spectrum of Pd-diimine@SBA-15 after being used four times is shown in Figure 1. The absorption band at 1622 1656 (the top at $1635 \mathrm{~cm}^{-1}$ ) was observed, which shows the existence of diimine@SBA-15 and Pd-diimine@SBA-15; that is to say, some Pd-diimine@SBA-15 was damaged and turned to supported $\operatorname{Pd}(0)$ and diimine@SBA-15 after being used four times. These are evidences accounting for the effect of diimine-functionalization on silica. With the help of diimine groups, Pd species could be anchored on the support tightly with high dispersion and stability, which greatly enhanced the catalytic activity and recyclability [41]. Thus, the mesoporous structure and organic functional groups grafted on the SBA-15 simultaneously improved the catalytic performance of Pd-diimine@SBA-15.

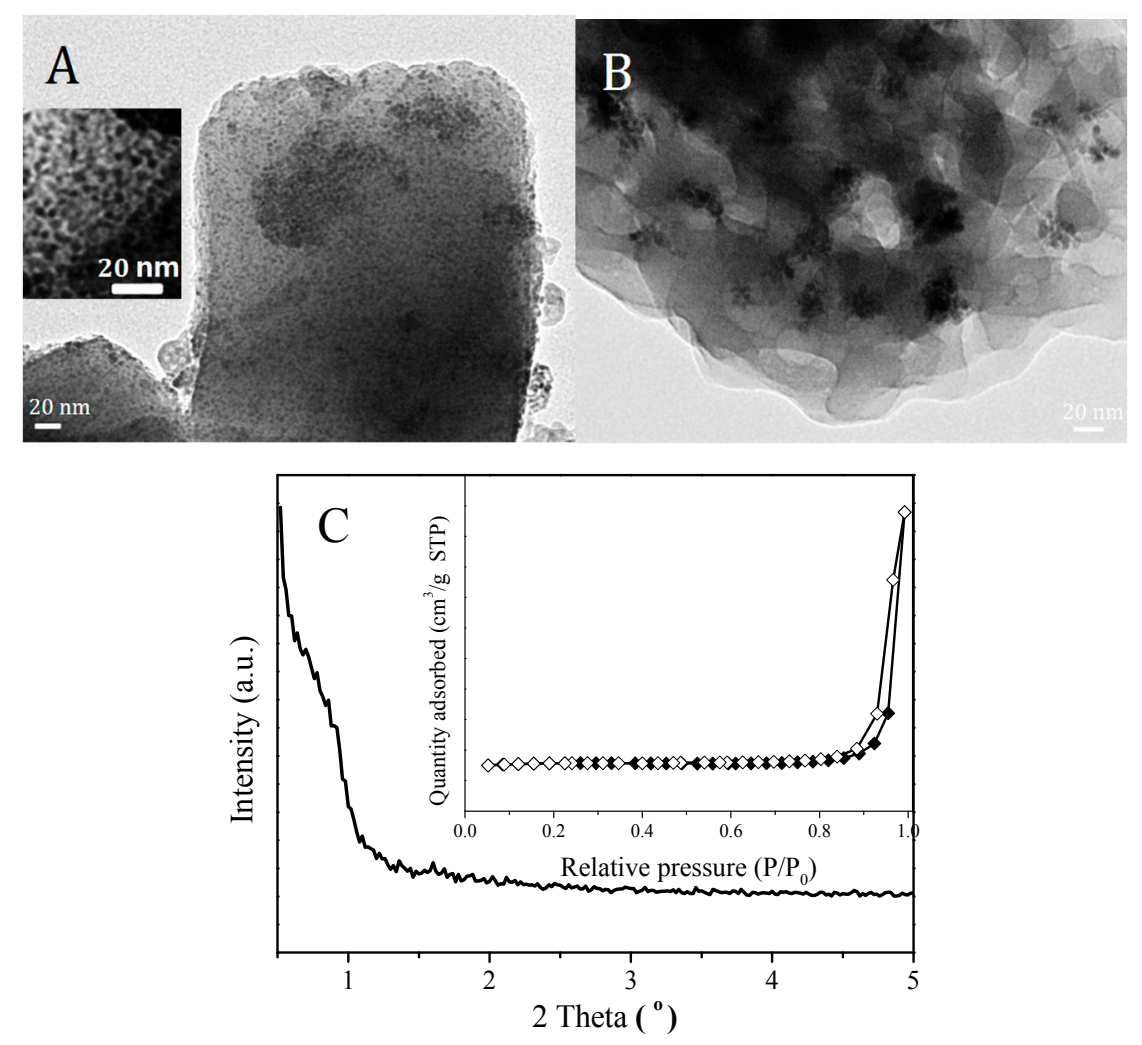

Figure 9. TEM images of (A) Pd-diimine@SBA-15 and (B) Pd/SBA-15 repeatedly used four times; (C) SA-XRD pattern and $\mathrm{N}_{2}$ sorption isotherm of Pd-diimine@SBA-15 repeatedly used four times.

Palladium leaching was also taken into consideration. After the reaction, the solid catalyst was filtrated, and the filtrate was measured by ICP; the results are shown in Table 4. The amount of leaching $\mathrm{Pd}$ in the reaction solution using Pd-diimine@SBA-15 catalyst (1.9-3.7 ppm, Pd leaching/Pd loading of $\sim 1 \%$ ) was lower than that using the Pd/SBA-15 catalysts (9.1-22.5 ppm, Pd leaching/Pd loading of $5 \% \sim 12 \%$ ). This result suggests that diimine groups can anchor palladium ions effectively.

The hot filtration test was done to check the reaction process. The test entails filtering a portion of the reaction solution to remove the catalyst before the reactants are added and the reaction is initiated. The results show that unfiltered portion still proceeded up to $87 \%$ yield, while the filtered portion could not react any more. When the reaction mixture after $2 \mathrm{~h}$ of the reaction proceeding at $80^{\circ} \mathrm{C}$ was filtered with $38 \%$ yield, the filtrate was further heated at $80{ }^{\circ} \mathrm{C}$ for $2 \mathrm{~h}$ and $8 \%$ yield was added on the basis of original yield. This shows that Pd leaching can catalyze this coupling reaction. Nevertheless, this test could lead to inaccurate conclusions if fast redeposition of soluble species occurs; if an induction period can be observed, due to an activation of the catalyst, the immobilized species is definitely not the active catalytic species [42]. 


\section{Experimental Section}

Triblock copolymer Pluronic P123 $\left(\mathrm{EO}_{20} \mathrm{PO}_{70} \mathrm{EO}_{20}\right)$ was purchased from Sigma-Aldrich (St. Louis, $\mathrm{MO}, \mathrm{USA}$ ) and 3-aminopropyl trimethoxysilane and others chemicals were obtained from Aladdin (Los Angeles, CA, USA). All chemicals were purchased as reagent grade from commercial suppliers and used without further purification, unless otherwise noted.

\subsection{Synthesis of Materials}

Synthesis of SBA-15. In a $250 \mathrm{~mL}$ round-bottomed flask, Pluronic P123 (4 g) was dissolved in the mixed solution of water $(30 \mathrm{~mL})$ and $2 \mathrm{M} \mathrm{HCl}(120 \mathrm{~mL})$ under stirring at room temperature for $2 \mathrm{~h}$. Then, the mixed solution was heated to $40{ }^{\circ} \mathrm{C}$, and $8.50 \mathrm{~g}$ tetraethyl orthosilicate (TEOS) was added under stirring. After this synthesis solution was stirred at $40{ }^{\circ} \mathrm{C}$ for $20 \mathrm{~h}$, it was aged at $100{ }^{\circ} \mathrm{C}$ for $24 \mathrm{~h}$ under static condition. The solid formed was filtered and dried at room temperature overnight. The template in as-synthesized sample was removed by washing twice with the mixed solution of hydrochloric acid and ethanol (1.5 g hydrochloric acid per $200 \mathrm{~mL}$ ethanol) under reflux for $6 \mathrm{~h}$ and designated as SBA-15 [43,44].

Synthesis of APTMS@SBA-15. In a $100 \mathrm{~mL}$ three-necked round-bottomed flask, 3-aminopropyl trimethoxysilane (APTMS) ( $8 \mathrm{~mL}, 45 \mathrm{mmol})$ was added dropwise to a suspension of SBA-15 (5 g) in dry toluene $(30 \mathrm{~mL})$ under a $\mathrm{N}_{2}$ atmosphere. This mixture solution was refluxed for $24 \mathrm{~h}$. After that, the solid was filtered and washed repeatedly with dichloromethane to remove the unreacted starting material, and dried in a vacuum oven at $120^{\circ} \mathrm{C}$ for $8 \mathrm{~h}$. The white powder obtained was designated as APTMS@SBA-15 [45].

Synthesis of diimine@SBA-15. In a $250 \mathrm{~mL}$ round-bottomed flask, glyoxal $(4 \mathrm{mmol})$ and formic acid (4 drops) was added to the suspension of APTMS@SBA-15 (4 g) in MeOH (100 mL). The mixture solution was refluxed for $4 \mathrm{~h}$. Then, the solid was filtered and washed repeatedly with ice-cold $\mathrm{MeOH}$ and dried at room temperature by infrared radiation. The yellow solid obtained was designated as diimine@SBA-15.

Synthesis of Pd-diimine@SBA-15. In a $100 \mathrm{~mL}$ round-bottomed flask, diimine@SBA-15 (0.4 g) was added to the mixture solution of $\mathrm{PdCl}_{2}(35.4 \mathrm{mg}, 0.2 \mathrm{mmol})$ in acetone $(40 \mathrm{~mL})$. After this mixture solution was stirred at room temperature for $24 \mathrm{~h}$, the solid was filtered and washed repeatedly with acetone until the eluate became colorless, and then dried at room temperature by infrared radiation. The light-orange solid obtained was designated as Pd-diimine@SBA-15. The Pd content in the Pd-diimine@SBA-15 catalyst was $5.8 \mathrm{wt} \%$ Pd, determined by ICP-OES. The samples above were prepared by the strategy shown in Scheme 1.

Synthesis of Pd/SBA-15. As a comparison sample, the Pd/SBA-15 catalyst was prepared. In a $100 \mathrm{~mL}$ round-bottomed flask, SBA-15 (0.4 g) was added to the mixed solution of $\mathrm{PdCl}_{2}$ $(35.4 \mathrm{mg}, 0.2 \mathrm{mmol})$ in acetone $(40 \mathrm{~mL})$. After this mixed solution was stirred at room temperature for $24 \mathrm{~h}$, the solid was filtered and washed repeatedly with acetone until the eluate became colorless, and then dried at room temperature by infrared radiation. The Pd content in the Pd/SBA-15 catalyst was $4.7 \mathrm{wt} \% \mathrm{Pd}$, determined by ICP-OES.

Synthesis of Pd-diimine@SiO 2 . As a comparison example, the Pd-diimine@SiO $\mathrm{S}_{2}$ catalyst was prepared by using the same method as Pd-diimine@SBA-15. In a $100 \mathrm{~mL}$ round-bottomed flask, diimine@ $\mathrm{SiO}_{2}(0.4 \mathrm{~g})$ was added to the mixture solution of $\mathrm{PdCl}_{2}(35.4 \mathrm{mg}, 0.2 \mathrm{mmol})$ in acetone $(40 \mathrm{~mL})$. After this mixture solution was stirred at room temperature for $24 \mathrm{~h}$, the solid was filtered and washed repeatedly with acetone until the eluate became colorless, and then dried at room temperature by infrared radiation. The Pd content in the Pd-diimine@SiO ${ }_{2}$ catalyst was $5.2 \mathrm{wt} \% \mathrm{Pd}$, determined by ICP-OES. 


\subsection{Characterization of Sample}

The Pd content of the catalyst was determined with an inductively coupled plasma optical emission spectroscopy (ICP-OES, Optima 7000DV, Perkin-Elmmer Co., Waltham, MA, USA) after the sample was dissolved in the HF solution. The FT-IR spectra were recorded on a Nicolet NEXUS 670 FT-IR spectrometer (Thermo Scientific Co., Madison, WI, USA), and the sample to be measured was ground with $\mathrm{KBr}$ and pressed into thin wafer. The $\mathrm{N}_{2}$ adsorption-desorption isotherms of samples were performed on a Micromeritics ASAP 2020 Sorptometer (Micromeritics Instrument Co., Norcross, GA, USA) using static adsorption procedures, and the surface areas of catalysts were calculated by the BET method. The pore-size distribution was calculated by Barrett-Joyner-Halanda (BJH) method. The single-point pore volume $(\mathrm{Vp})$ of sample was estimated based on the amount adsorbed at the relative pressure of $\mathrm{P} / \mathrm{P}_{0}=0.989$. The X-ray diffractions (XRD) patterns of catalysts were performed on a PANalytical PW3040/60 X'pert PRO diffractometer (PANalytical, Almelo, Netherlands) with Cu $K \alpha$ radiation. Scanning electron microscopy (SEM) images of samples were taken on a Hitachi S4800 scanning electron microscope. Transmission electron microscopy (TEM) images were obtained on a JEOL JEM-2100 microscope (JEOL, Tokyo, Japan), and the sample to be measured was first dispersed in ethanol and then collected on a copper grids covered with carbon film.

\subsection{Suzuki Coupling Reactions of Aryl Halides over Supported Pd Catalyst}

Aryl halide $(3 \mathrm{mmol})$, arylboronic acid $(3.3 \mathrm{mmol}), \mathrm{K}_{3} \mathrm{PO}_{4}(4.5 \mathrm{mmol})$, catalyst (appropriate quantity), and solvent $(6 \mathrm{~mL})$ were added in a $50 \mathrm{~mL}$ two-necked round-bottomed flask under a $\mathrm{N}_{2}$ atmosphere and stirring. After this mixture solution was heated to $80^{\circ} \mathrm{C}$ in an oil bath under stirring, the Suzuki coupling reaction occurred at $80^{\circ} \mathrm{C}$ for 3-12 $\mathrm{h}$. After the reaction was finished, the catalyst was separated by filtration immediately, and washed by deionized water, ethanol, and diethyl ether, successively. After drying in air, the recovered catalyst could be used repeatedly in the Suzuki coupling reaction. The filtrate was extracted with ethyl acetate, which was uncolored and clear, and no catalyst particles could be observed. The solvent was evaporated and the resultant crude products were purified by silica column chromatography with hexane as eluent. The reactant conversion and product selectivity were determined by gas chromatograph (GC-950, Shanghai, China) equipped with a flame ionization detector (FID) and the method of correction area.

\section{Conclusions}

In summary, the highly efficient Pd-diimine@SBA-15 catalyst for Suzuki coupling reactions has been successfully prepared by immobilizing Pd species onto diimine-functionalized mesoporous SBA-15, in which the Pd species were atomically dispersed on support. The Pd-diimine@SBA-15 catalyst exhibited high-efficient catalytic performance for the Suzuki coupling reaction of electronically diverse aryl halides and phenylboronic acid under mild conditions with an ultralow amount of $\mathrm{Pd}(0.05 \mathrm{~mol} \% \mathrm{Pd})$. High yield of product can be obtained for almost all coupling reactions of bromobenzene with electron-withdrawing and -donating substituents and phenylboronic acid. When the amount of catalyst was increased to $1 \mathrm{~mol} \% \mathrm{Pd}$, this catalyst can catalyze the coupling reaction of chlorinated aromatics and phenylboronic acid. Compared with the catalytic performances of Pd/SBA-15 and Pd-diimine@SiO 2 catalysts, the Pd-diimine@SBA-15 catalyst exhibited higher hydrothermal stability and could be repeatedly used four times without significant decrease of its catalytic activity. This study might offer a new strategy for synthesis of supported metal catalysts on different types of mesoporous silica.

Acknowledgments: Financial supports from Shanghai Municipal Science and Technology Commission (12NM0504500 and 13XD1421700) are gratefully acknowledged.

Author Contributions: All authors conceived the idea for the work and designed the experiments. G.L. and Y.C. directed the experiments; J.Y. and A.S. performed the experiments; J.Y. and G.L. wrote the manuscript. All authors contributed to the analysis and interpretation of the results. 
Conflicts of Interest: The authors declare no conflict of interest.

\section{References}

1. Miyaura, N.; Yamada, K.; Suzuki, A. A new stereospecific cross-coupling by the palladium-catalyzed reaction of 1-alkenylboranes with 1-alkenyl or 1-alkynyl halides. Tetrahedron Lett. 1979, 20, 3437-3440. [CrossRef]

2. Miyaura, N.; Suzuki, A. Palladium-catalyzed cross-coupling reactions of organoboron compounds. Chem. Rev. 1995, 95, 2457-2483. [CrossRef]

3. Navarro, O.; Kaur, H.; Mahjoor, P.; Nolan, S.P. Cross-coupling and dehalogenation reactions catalyzed by ( $N$-heterocyclic carbene) Pd (allyl) Cl complexes. J. Org. Chem. 2004, 69, 3173-3180. [CrossRef] [PubMed]

4. Braga, A.A.C.; Morgon, N.H.; Ujaque, G.; Maseras, F. Computational characterization of the role of the base in the Suzuki-Miyauracross-Coupling Reaction. J. Am. Chem. Soc. 2005, 127, 9298-9307. [CrossRef] [PubMed]

5. Bonnet, S.; Lutz, M.; Spek, A.L.; Koten, G.V.; KleinGebbink, R.J.M. Bimetallic $\eta 6, \eta 1$-and PCP-pincer Ruthenium Palladium complexes: Synthesis, structure, and catalytic activity. Organometallics 2010, 29, 1157-1167. [CrossRef]

6. Sabater, S.; Mata, J.A.; Peris, E. Coordination singularities of a bis(p-xylyl)bis(benzimidazolylidene) ligand and the bis-iridium and rhodium-related complexes. Organometallics 2013, 32, 1112-1120. [CrossRef]

7. Shen, A.; Ni, C.; Cao, Y.C.; Zhou, H.; Song, G.H.; Ye, X.F. Novel monoligated imine-Pd-NHC complexes: Extremely active pre-catalysts for Suzuki-Miyaura coupling of aryl chlorides. Tetrahedron Lett. 2014, 55, 3278-3282. [CrossRef]

8. Molnár, Á. Efficient, Selective, and recyclable palladium catalysts in carbon-carbon coupling reactions. Chem. Rev. 2011, 111, 2251-2320.

9. Narayanan, R.; El-Sayed, M.A. Effect of catalysis on the stability of metallic nanoparticles: Suzuki reaction catalyzed by PVP-palladium nanoparticles. J. Am. Soc. Chem. 2003, 125, 8340-8347. [CrossRef] [PubMed]

10. Narayanan, R.; El-Sayed, M.A. Effect of colloidal catalysis on the nanoparticle size distribution: Dendrimer-Pd vs. PVP-Pd nanoparticles catalyzing the Suzuki coupling reaction. J. Phys. Chem. B 2004, 108, 8572-8580. [CrossRef]

11. Bakherad, M.; Keivanloo, A.; Bahramian, B.; Jajarmi, S. Suzuki, Heck, and copper-free Sonogashira reactions catalyzed by 4-amino-5-methyl-3-thio-1, 2, 4-triazole-functionalized polystyrene resin-supported Pd (II) under aerobic conditions in water. J. Org. Chem. 2013, 724, 206-212. [CrossRef]

12. Kim, J.H.; Kim, J.W.; Shokouhimehr, M.; Lee, Y.S. Polymer-Supported N-Heterocyclic Carbene-Palladium Complex for Heterogeneous Suzuki Cross-Coupling Reaction. J. Org. Chem. 2005, 70, 6714-6720. [CrossRef] [PubMed]

13. Shokouhimehr, M.; Kim, J.H.; Lee, Y.S. Heterogeneous Heck Reaction Catalyzed by Recyclable Polymer-Supported N-Heterocyclic Carbene-Palladium Complex. Synlett 2006, 37, 618-620. [CrossRef]

14. Corma, A.; Garcia, H.; Leyva, A. Catalytic activity of palladium supported on single wall carbon nanotubes compared to palladium supported on activated carbon: Study of the Heck and Suzuki couplings, aerobic alcohol oxidation and selective hydrogenation. J. Mol. Catal. A Chem. 2005, 230, 97-105. [CrossRef]

15. Jun, S.W.; Shokouhimehr, M.; Lee, D.J.; Jang, Y.; Park, J.; Hyeon, T. One-pot synthesis of magnetically recyclable mesoporous silica supported acid-base catalysts for tandem reactions. Chem. Commun. 2013, 49, 7821-7823. [CrossRef] [PubMed]

16. Kim, A.; Rafiaei, S.M.; Abolhosseini, S.; Shokouhimehr, M. Palladium Nanocatalysts Confined in Mesoporous Silica for Heterogeneous Reduction of Nitroaromatics. Energy Environ. Focus 2015, 4, 18-23. [CrossRef]

17. Shokouhimehr, M. Magnetically Separable and Sustainable Nanostructured Catalysts for Heterogeneous Reduction of Nitroaromatics. Catalysts 2015, 5, 534-560. [CrossRef]

18. Gruttadauria, M.; Liotta, L.F.; Salvo, A.M.P.; Giacalone, F.; Parola, V.L.; Aprile, C.; Noto, R. Multi-Layered, covalently supported ionic liquid phase (mlc-SILP) as highly cross-linked support for recyclable palladium catalysts for the Suzuki reaction in aqueous medium. Adv. Synth. Catal. 2011, 353, 2119-2130. [CrossRef]

19. Wang, P.Y.; Wang, Z.Y.; Li, J.G.; Bai, Y.X. Preparation, characterization, and catalytic characteristic of Pdnanoparticles encapsulated in mesoporoussilica. Microp. Mesop. Mater. 2008, 116, 400-405. [CrossRef]

20. Ma, C.Y.; Dou, B.J.; Li, J.J.; Cheng, J.; Hu, Q.; Hao, Z.P.; Qiao, S.Z. Catalytic oxidation of benzyl alcohol on Au or Au-Pdnanoparticles confined in mesoporoussilica. Appl. Catal. B Environ. 2009, 92, 202-208. [CrossRef] 
21. Mubofu, E.B.; Clark, J.H.; Macquarrie, D.J. A novel Suzuki reaction system based on a supported palladium catalyst. Green Chem. 2001, 3, 23-25. [CrossRef]

22. Paul, S.; Clark, J.H. Highly active and reusable heterogeneous catalyst for the Suzuki reaction: Synthesis of biaryls and polyaryls. Green Chem. 2003, 5, 635-638. [CrossRef]

23. Sarmah, C.; Sahu, D.; Das, P. Anchoring palladium acetate onto imine-functionalized silica gel through coordinative attachment: An effective recyclable catalyst for the Suzuki-Miyaura reaction in aqueous-isopropanol. Catal. Today 2012, 198, 197-203. [CrossRef]

24. Mahouche-Chergui, S.; Ledebt, A.; Mammeri, F.; Herbst, F.; Carbonnier, B.; Ben Romdhane, H.; Delamar, M.; Chehimi, M.M. Hairy carbon nanotube@nano-Pd heterostructures: Design, characterization, and application in Suzuki C-C coupling reaction. Langmuir 2010, 26, 16115-16121. [CrossRef] [PubMed]

25. Kong, G.Q.; Ou, S.; Zou, C.; Wu, C.D. Assembly and post-modification of a metal-organic nanotube for highly efficient catalysis. J. Am. Chem. Soc. 2012, 134, 19851-19857. [CrossRef] [PubMed]

26. Huang, J.L.; Yin, J.W.; Chai, W.; Liang, C.; Shen, J.; Zhang, F. Multifunctional mesoporous silica supported palladium nanoparticles as efficient and reusable for water-medium Ullmann reaction. New J. Chem. 2012, 36, 1378-1384. [CrossRef]

27. Yang, H.Q.; Han, X.J.; Li, G.; Wang, Y.W. N-Heterocyclic carbenepalladium complex supported on ionic liquid-modified SBA-16: An efficient and highly recyclable catalyst for the Suzuki and Heck reactions. Green Chem. 2009, 11, 1184-1193. [CrossRef]

28. Yang, H.Q.; Han, X.J.; Li, G.; Ma, Z.C.; Hao, Y.J. Mesoporous ethane-silicas functionalized with a Bulky $\mathrm{N}$-Heterocyclic carbene for Suzuki-Miyaura coupling of aryl chlorides and benzyl chlorides. J. Phys. Chem. C 2010, 114, 22221-22229. [CrossRef]

29. Ghorbani-Vaghei, R.; Hemmati, S.; Veisi, H. Pd Immobilized on amidioxime- functionalized mesoporous SBA-15: A novel and highly active heterogeneous catalyst for Suzuki-Miyauracoupling reactions. J. Mol. Catal. A Chem. 2014, 393, 240-247. [CrossRef]

30. Crudden, C.M.; Sateesh, M.; Lewis, R. Mercaptopropyl-modified mesoporoussilica: A remarkable support for the preparation of a reusable, heterogeneous palladium catalyst for coupling reactions. J. Am. Chem. Soc. 2005, 127, 10045-10050. [CrossRef] [PubMed]

31. Webb, J.D.; MacQuarrie, S.; McEleney, K.; Crudden, C.M. Mesoporous Silica-Supported Pd Catalysts: An Investigation into Structure, Activity, Leaching and Heterogeneity. J. Catal. 2007, 252, 97-109. [CrossRef]

32. Veisi, H.; Hamelian, M.; Hemmati, S. Palladium anchored to SBA-15 functionalized with melamine-pyridine groups as anovel and efficient heterogeneous nanocatalyst for Suzuki-Miyaura coupling reactions. J. Mol. Catal. A Chem. 2014, 395, 25-33. [CrossRef]

33. Alonso, F.; Beletskaya, P.; Yus, M. Non-conventional methodologies for transition-metal catalysed carbon-carbon coupling: A critical overview. Part 2: The Suzuki reaction. Tetrahedron 2008, 64, 3047-3101. [CrossRef]

34. Bass, J.D.; Solovyov, A.; Pascall, A.J.; Katz, A. Acid-basebifunctional and dielectric outer-sphere effects in heterogeneous catalysis: A comparative investigation of model primary amine catalysts. J. Am. Chem. Soc. 2006, 128, 3737-3747. [CrossRef] [PubMed]

35. Jiang, Y.; Gao, Q.; Yu, H.; Chen, Y.; Deng, F. Intensively competitive adsorption for heavy metal ions by PAMAM-SBA-15 and EDTA-PAMAM-SBA-15 inorganic-organic hybrid materials. Microp. Mesop. Mater. 2007, 103, 316-324. [CrossRef]

36. Poel, H.V.D.; Koten, G.V.; Vrieze, K. Novel bonding modes of $\alpha$-diimines. Synthesis and characterization of $\left[\mathrm{MCl}_{2} \mathrm{~L}(\alpha\right.$-diimine $\left.)\right]$ and $\left[\mathrm{MCl}_{2}(\alpha\right.$-diimine $\left.) \mathrm{n}\right](M=\mathrm{Pd}, \mathrm{Pt} ; L=$ phosphine, arsine; $n=1,2)$ containing $\sigma, \sigma-N, N^{\prime}, \sigma-\mathrm{N}$, or $\sigma-N \leftrightarrow \sigma-N^{\prime}$ bonded $\alpha$-diimines. Inorg. Chem. 1980, 19, 1145-1151. [CrossRef]

37. Zhang, G.H.; Wang, P.Y.; Wei, X.F. Palladium supported on functionalized mesoporous silica as an efficient catalyst for Suzuki-Miyauracoupling reaction. Catal. Lett. 2013, 143, 1188-1194. [CrossRef]

38. Hu, Q.Y.; Hampsey, J.E.; Jiang, N.; Li, C.J.; Lu, Y.F. Surfactant-Templated organic functionalized mesoporous silica with phosphinoligands. Chem. Mater. 2005, 17, 1561-1569. [CrossRef]

39. Shi, X.J.; Ji, S.F.; Wang, K.; Li, C.Y. Oxidative Dehydrogenation of Ethane with $\mathrm{CO}_{2}$ over Novel $\mathrm{Cr} / \mathrm{SBA}-15 / \mathrm{Al}_{2} \mathrm{O}_{3} / \mathrm{FeCrAl}$ Monolithic Catalysts. Energy Fuels 2008, 22, 3631-3638. [CrossRef]

40. Navarro, O.; Marion, N.; Oonishi, Y.; Kelly, R.A.; Nolan, S.P. Suzuki-Miyaura, $\alpha$-Ketone Arylation and Dehalogenation Reactions Catalyzed by a Versatile N-Heterocyclic Carbene-Palladacycle Complex. J. Org. Chem. 2006, 71, 685-692. [CrossRef] [PubMed] 
41. Li, P.; Liu, H.; Yu, Y.; Cao, C.Y.; Song, W.G. One-Pot multistep cascade reactions over multifunctional nanocomposites with Pd nanoparticles supported on amine-modified mesoporous silica. Chem. Asian J. 2013, 8, 2459-2465. [CrossRef] [PubMed]

42. Taladriz-Blanco, P.; Hervés, P.; Pérez-Juste, J. Supported Pd Nanoparticles for Carbon-Carbon Coupling Reactions. Top. Catal. 2013, 56, 1154-1170.

43. Zhao, D.Y.; Huo, Q.S.; Feng, J.L.; Chmelka, B.F.; Stucky, G.D. Nonionic triblock and star diblock copolymer and oligomeric surfactant syntheses of highly ordered, hydrothermally stable, mesoporous silica structures. J. Am. Chem. Soc. 1998, 120, 6024-6036. [CrossRef]

44. Melero, J.A.; Stucky, G.D.; Grieken, R.V.; Morales, G. Direct syntheses of ordered SBA-15 mesoporous materials containing arenesulfonic acid groups. J. Mater. Chem. 2002, 12, 1664-1670. [CrossRef]

45. Isfahani, A.L.; Mohammadpoor-Baltork, I.; Mirkhani, V.; Khosropour, A.R.; Moghadam, M.; Tangestaninejad, S.; Kia, R. Palladium nanoparticles immobilized on nano-Silica triazinedendritic polymer (Pdnp-nSTDP): An efficient and reusable catalyst for Suzuki-Miyauracross-coupling and Heck reactions. Adv. Synth. Catal. 2013, 355, 957-972. [CrossRef]

(C) 2016 by the authors; licensee MDPI, Basel, Switzerland. This article is an open access article distributed under the terms and conditions of the Creative Commons Attribution (CC-BY) license (http://creativecommons.org/licenses/by/4.0/). 